\title{
Efficacy of Biological Control and Cultivar Resistance on Fusarium Head Blight and T-2 Toxin Contamination in Wheat
}

\author{
Scholastica Leah Musyimi ${ }^{1}$, James Wanjohi Muthomi ${ }^{2 *}$, Rama Devi Narla ${ }^{2}$, John Maina Wagacha ${ }^{3}$ \\ ${ }^{1}$ Ministry of Agriculture, Nairobi, Kenya; ${ }^{2}$ Department of Plant Science and Crop Protection, University of Nairobi, Nairobi, Kenya; \\ ${ }^{3}$ School of Biological Sciences, University of Nairobi, Nairobi, Kenya.

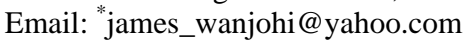

Received December $26^{\text {th }}, 2011$; revised January $19^{\text {th }}, 2012$; accepted February $16^{\text {th }}, 2012$

\begin{abstract}
Laboratory and green house experiments were carried out to evaluate the efficacy of fungicides, biological agents and host resistance in managing FHB and the associated T-2 toxin. In vitro activity of fungicides and antagonists was determined by paired culture method. Effect of microbial agents on FHB severity and mycotoxin content was determined by co-inoculating F. graminearum and F. poae with Alternaria spp., Epicoccum spp. and Trichoderma spp. Fungicides Pearl $^{\circledR}$ (500 g/L carbendazim), Cotaf ${ }^{\circledR}$ (50 g/L hexaconacole), Thiovit ${ }^{\circledR}$ (micronised sulphur $80 \% \mathrm{w} / \mathrm{w}$ ) and Folicur ${ }^{\circledR}$ (430 g/L tebuconazole) were the standard checks. Host resistance was determined by inoculating $F$. poae and $F$. graminearum to four wheat cultivars and fifteen lines in pot experiments. Fungicides resulted in 100\% inhibition of pathogen radial growth in in vitro while microbial agents suppressed pathogen growth by up to $53 \%$. Thiovit ${ }^{\circledR}$ and Trichoderma were the most effective in reducing FHB severity in green house pot experiments. The wheat cultivars and lines varied in susceptibility with cultivar Njoro BW II showing least susceptibility while line R1104, cv. Mbuni and cv. KIBIS were most susceptible. All the wheat cultivars and lines accumulated T-2 toxin by up to 5 to $28 \mu \mathrm{g} / \mathrm{kg}$. The results indicated that neither fungicides nor antagonists can solely be relied on in managing FHB and toxin accumulation. Therefore, integration of biocontrol agents, fungicides and further breeding efforts to improve lines and cultivars with promising resistance to FHB and T2-toxin contamination is recommended.
\end{abstract}

Keywords: Antagonists; Fungicides; Fusarium Head Blight; T-2 Toxin; Wheat

\section{Introduction}

Fusarium head blight (FHB) of wheat and other small grain cereals is caused by a complex of Fusarium spp. resulting in decreased yield, bleached and shrunken kernels and decreased seed quality [1,2]. The disease also leads to accumulation of mycotoxins that have adverse effects on human and animal health [3,4]. In wheat, the major mycotoxins associated with the disease are trichothecenes (T-2 toxin, deoxynivalenol and nivalenol) as well as zearalenone and fumonisins [4,5]. Trichothecenes are involved in inhibition of the host resistance reactions $[6,7]$.

Management of FHB and the associated mycotoxins have been based on strategies such as host resistance, use of biological agents, tillage, seed treatment, crop rotation and fungicides [8-10]. Control of FHB using fungicides has provided inconsistent results due to the complexity of causal organisms, influence of $\mathrm{N}$-fertilization, timing of

${ }^{*}$ Corresponding author. application and masking control of one Fusarium species by the subsequent growth of another species [10-12]. The most susceptible growth stage of wheat to FHB is anthesis and residue concerns regarding the use of fungicides late in crop development lessen their attractiveness [13, 14]. The most promising option for managing FHB remains breeding for resistance [15]. Although there have been advances in breeding for resistance, all wheat cultivars currently in production are susceptible to the disease $[15,16]$. However, some cultivars have useable levels of partial resistance that limit yield loss and mycotoxin accumulation $[17,18]$.

Additionally, there have been efforts to identify biological antagonists, which could be used in integrated pest management strategies [19,20]. Biological control of pathogens responsible for FHB holds considerable promise and entails treatment of crop residues with antagonists to reduce pathogen inoculum [21] and wheat heads at anthesis to reduce infection [22,23]. Biological control of FHB is attractive since it is environmentally benign, 
compatible with other control measures, and durable. In previous studies, various fungal and bacterial microbes have shown potential as biocontrol agents in the management of FHB. Such antagonists include Clostachys rosae, Phoma betae and Pseudomonas fluorescens among others $[19,20,22,24]$. This study was carried out to evaluate the efficacy of various management strategies-fungicides, biological control and host resistance-of FHB of wheat and the associated T2-toxin.

\section{Materials and Methods}

\subsection{Preparation of Inoculum and Inoculation}

Inoculum of 10 highly pathogenic $F$. graminearum and $F$. poae isolates was multiplied in mung bean broth [25]. Forty grams of mung bean was cooked in $1000 \mathrm{~mL}$ of sterile distilled water for 40 minutes which was then cooled and the extract sieved using double layer cheesecloth. A hundred milliliters of the extract were autoclaved in $250 \mathrm{~mL}$ conical flask at $121^{\circ} \mathrm{C}$ for 20 minutes. After cooling, two agar discs of the pathogen were placed in each conical flask and the suspension was incubated on mechanical shaker (40 - 50 cycles $\cdot \mathrm{min}^{-1}$ ) for 5 days followed by 7 days under stationary conditions. The fungal growth was macerated in a blender and sieved through double layer cheese cloth. Spore concentration was adjusted to $1 \times 10^{6}$ spores $/ \mathrm{mL}$ using a haemocytometer. A mixed inoculum was obtained by mixing suspension of different isolates of $F$. graminearum and $F$. poae and applied to wheat ears in the greenhouse at flowering stage (GS 65) [26]. Epicoccum, Alternaria and Trichoderma spp. were grown on potato dextrose agar (PDA) for 14 days at $25^{\circ} \mathrm{C}$ in cycles of $12 \mathrm{~h}$ daylight and $12 \mathrm{~h}$ darkness. Spores of the antagonists were harvested by flooding the cultures with sterile distilled water and sieved through a double layer of cheese cloth. The fungal inoculum was adjusted to $1 \times 10^{6}$ spores/L using haemocytometer.

\subsection{In Vitro Screening of Antagonists against FHB Pathogens}

Epicoccum spp, Trichoderma spp, Penicilium spp. and Alternaria spp. were screened for antagonism to $F$. graminearum and $F$. poae isolates in culture by paired cultures method, where $F$. graminearum and $F$. poae agar discs were inoculated at the middle of plate and the antagonist placed at four equidistant points $2 \mathrm{~cm}$ from the edge of the plate. Fungicides Pearl ${ }^{\circledR}$ (500 g/L carbendazim), Cotaf ${ }^{\circledR}$ (50 g/L hexaconacole), Thiovit ${ }^{\circledR}$ (micronised sulphur $80 \% \mathrm{w} / \mathrm{w})$ and Folicur ${ }^{\circledR}$ (430 g/L tebuconazole) at the rates of $1 \mathrm{~mL} / \mathrm{L}, 5 \mathrm{~mL} / \mathrm{L}, 2 \mathrm{~g} / \mathrm{L}$ and 1 $\mathrm{mL} / \mathrm{L}$, respectively, were used as standard checks. Folicur $^{\circledR}$ was only included in the in vitro assays. Negative controls consisted of $F$. graminearum and F. poae each cultured alone. Each treatment was replicated four times and the plates incubated at $25^{\circ} \mathrm{C}$ for 7 days in cycles of $12 \mathrm{~h}$ daylight and $12 \mathrm{~h}$ darkness. Degree of antagonism was determined by measuring the antagonist colony diameters and percentage inhibition calculated as follows:

$$
\text { Inhibition }(\%)=\frac{\text { Colony diameter of Pathogen }-[\text { Colony diameter of the pathogen }+ \text { Antagonist }]}{\text { Colony diameter of Pathogen alone }}
$$

\subsection{Determination of Efficacy of Fungal Antagonists and Fungicides against Fusarium Head Blight}

Trichoderma, Alternaria and Epicoccum species found to be effective antagonists to $F$. graminearum and $F$. poae in vitro were evaluated for potential reduction of FHB and T-toxin accumulation under green house conditions. Fungicides Pearl ${ }^{\circledR}$ (500 g/L carbendazim), Cotaf ${ }^{\circledR}$ (50 g/L hexaconacole) and Thiovit ${ }^{\circledR}$ (micronised sulphur 80\% $\mathrm{w} / \mathrm{w}$ ) that are normally used in managing other fungal diseases in wheat were also evaluated for potential reduction of FHB and T2-toxin under green house conditions. Highly and lowly susceptible wheat cultivars namely Mbuni and Njoro BW II, respectively were planted and replicated four times in greenhouse. Inoculation was done at 50\% flowering (GS 65) [26].

Treatments consisted of spraying the ears with Trichoderma; Alternaria and Epicoccum spp. together with F. graminearum and $F$. poae, F. graminearum and $F$. poae together with Pearl ${ }^{\circledR}$, Cotaf ${ }^{\circledR}$ and Thiovit ${ }^{\circledR}$ fungicides at the rates of $1 \mathrm{~mL} / \mathrm{L}, 5 \mathrm{~mL} / \mathrm{L}$ and $2 \mathrm{~g} / \mathrm{L}$, respectively and F. graminearum and $F$. poae alone. Control plants were sprayed with fungicide alone or sterile distilled water. The antagonists and fungicides were sprayed two days before and after inoculation with $F$. graminearum and $F$. poae. Inoculation with a mixture of $F$. graminearum and $F$. poae was repeated 6 days after the first inoculation. Each treatment was replicated four times and arranged in randomized complete block design. The treated heads were covered with polythene bags for 48 hrs to maintain high relative humidity conducive for infection.

\subsection{Evaluation of Wheat Lines for Susceptibility to FHB}

Wheat seeds of fifteen lines and four cultivars were obtained from the National Plant Breeding Research Station of the Kenya Agricultural Research Institute (K. A. R. I), Njoro. The cultivars included KIBIS, Mbuni, Njoro BW I and Njoro BW II while the lines were R1098, R1107, R1111, R1112, R1114, R1115, R1119, R1121, R1100, 
R1128, R1130, R1101, R1104, R1105 and R1106. Twenty seeds per pot $(\varnothing 20 \mathrm{~cm})$ were planted in forest soil/farm yard manure medium $(2: 1 \mathrm{v} / \mathrm{v})$ and grown outside the greenhouse until flowering to simulate field conditions. The plants were fertilized at different growth stages using urea $(46 \% \mathrm{~N}) 5 \mathrm{~g}$ per pot after emergence, $\mathrm{N}-\mathrm{P}-\mathrm{K} 5 \mathrm{~g}$ per pot at tillering, urea $(46 \% \mathrm{~N}) 5 \mathrm{~g}$ per pot at booting. Foliage pests were controlled as required using Danadim $^{\circledR}$ (dimethoate) applied at $2.5 \mathrm{~mL} / \mathrm{L}$. The flowering dates for the different varieties and lines were synchronized by early and late planting of late maturing and early maturing varieties/lines, respectively. The wheat ears were spray-inoculated with a mixture of F. graminearium and $F$. poae spore suspension at $50 \%$ flowering (GS65) [26], ensuring that all the spikelets were exposed to the inoculum. Ears of control plants were sprayed with sterile distilled water. Each treatment was replicated four times. The ears were covered with polythene bags for 48 hrs to maintain high relative humidity for infection. The experiments were conducted in two greenhouse cropping cycles.

\subsection{Fusarium Head Blight Assessment}

In each pot, ten average-sized ears were selected and tagged for FHB and grain weight assessment. Fusarium head blight severity was assessed visually after every seven days until yellow ripening based on a 1 - 9 scale (Miedaner, 1997): $1=$ no symptoms; $2=<5 \%$; $3=5 \%$ $15 \% ; 4=16 \%-25 \% ; 5=26 \%-45 \% ; 6=46 \%-65 \% ; 7$ $=66 \%-85 \%$; $8=86 \%-95 \%$; $9=96 \%-100 \%$ of spikelets bleached. The area under the disease progress curve (AUDPC) was calculated from the disease severity [27]:

$$
\text { AUDPC }=\sum_{i=1}^{n}\left[\left(Y_{i+1}+Y_{i}\right)\right]\left[\left(t_{i+1}-t_{i}\right)\right]
$$

where, $Y_{i}$ is the visual score of FHB symptoms at the $i$ th observation date and $t_{i}$ is the time (days) at the ith observation, $n$ is the total number of observations. At maturity the ears in each pot ten ears were harvested and threshed separately to determine the total grain weight per pot and grain weight for the ten ears assessed for FHB. Kernel infection with $F$. graminearum and $F$. poae in the harvested grain was determined by plating 100 kernels for each treatment on PDA medium.

\subsection{T-2 Toxin Analysis}

Concentration of T-2 toxin in wheat grains was analyzed by direct competitive Enzyme-Linked Immunosorbent Assay (ELISA) [28,29]. Each sample was homogenized and $100 \mathrm{~g}$ sub-sample ground to fine powder. Five grams of the ground sample was extracted with $25 \mathrm{~mL}$ of methanol: water $(70 / 30 \mathrm{v} / \mathrm{v})$ for T-2 toxin. The extract was de-fatted with $10 \mathrm{~mL}$ hexane, and $4 \mathrm{~mL}$ of the methano- lic layer was diluted to $10 \%$ using phosphate buffer solution. The methanolic extract was diluted with an equal volume of distilled water. A commercial kit (Ridascreen, r-Biopharm, Germany) was used and the ELISA procedure performed following the manufacturer's recommendations. Absorbance was determined using the spectrophotometer ELISA reader (Uniskan II, Finland) at 450 $\mathrm{nm}$. A calibration curve for the standards for each toxin dilution was plotted using log 10 of standards concentration against the percentage inhibition of the standards.

\subsection{Data Analysis}

All data were subjected to analysis of variance (ANOVA) using the PROC ANOVA procedure of Genstat (VSN International limited, 2008 edition III). Differences among treatment means were separated using the Fisher's protected LSD test at 5\% probability level. Where necessary, data was transformed to square root using the formula; $=\mathrm{SQT}(\mathrm{n}+0.5)$, where: $\mathrm{n}$ is the number of observations and SQT is square root and 0.5 is a constant.

\section{Results}

\subsection{In Vitro Activity of Biological and Chemical Agents against FHB Pathogens}

All the fungicides reduced the radial growth of colonies of both $F$. poae and $F$. graminearum by $100 \%$, but the microbial agents differed significantly $(p<0.05)$ (Table 1). However, the fungicides were significantly $(p<0.05)$ more effective in reducing the colony diameters than the biological agents. Epicoccum and Penicillium spp. had the highest and lowest colony growth reductions for $F$. poae, respectively while Trichoderma had the greatest inhibitory effect on F. graminearum compared to Penicilium which had $24 \%$ reduction in colony growth.

\subsection{Effectiveness of Antagonists and Chemical Agents in Reducing FHB}

Disease severity increased over time on all the treatments

Table 1. Average percentage colony diameter reduction of $F$. poae and $F$. graminearum by different competitive fungi and fungicides.

\begin{tabular}{ccc}
\hline Organism/Fungicide & F. poae & F. graminearum \\
\hline Trichoderma & 62.6 & 53.4 \\
Epicoccum & 64.9 & 45.7 \\
Alternaria & 60.1 & 49.3 \\
Penicilium $^{*}$ & 21.8 & 24.8 \\
Thiovit $^{\circledR}$ & 100.0 & 100.0 \\
Folicur $^{\circledR}$ & 100.0 & 100.0 \\
Cotaf $^{\circledR}$ & 100.0 & 100.0 \\
Pearl $^{\circledR}$ & 100.0 & 100.0 \\
\hline
\end{tabular}

*Significantly different $(\mathrm{p}<0.05)$ within columns. 
for both cultivars Mbuni and Njoro BW II (Table 2). There were significant ( $\mathrm{p}<0.05$ ) differences in FHB severity only on the seventh day after inoculation for $\mathrm{cv}$. Mbuni but for cv. Njoro BW II, there were significant ( $\mathrm{p}$ $<0.05 ; \mathrm{n}=40$ ) differences over the disease assessment period among all the treatments. The highest FHB severity reduction of up to $76 \%$ and $69 \%$ was observed on $\mathrm{cV}$. Njoro BW II treated with Epicoccum and Thiovit ${ }^{\circledR}$, respectively.

Trichoderma and Thiovit ${ }^{\circledR}$ were the most effective antagonist and fungicide, respectively in reducing FHB severity on cv. Mbuni. Fungal mixture of the antagonists was not effective $(p<0.05)$ in reducing the disease compared to the control. On the other hand, Epicoccum and Thiovit ${ }^{\circledR}$ had the highest average disease severity reduction on $\mathrm{cV}$. Njoro BW II. The area under disease progress curve (AUDPC) was significantly ( $p<0.05$ ) different among the treatments for cultivars Mbuni and Njoro BW II (Table 3). The highest and lowest AUDPC of 561 and 416 on cv. Mbuni treated with Pearl ${ }^{\circledR}$ and Trichoderma, respectively. For cv. Njoro BW II, treatment with Pearl ${ }^{\circledR}$ and Epicoccum resulted in the highest and lowest AUDPC of 545 and 295, respectively. However, treatment with

Table 2. Disease severity rating over time on wheat ears (cv. Mbuni and cv. Njoro BW II) inoculated with F. poae and F. graminearum.

\begin{tabular}{|c|c|c|c|c|c|}
\hline \multirow{2}{*}{ Organism/Fungicide } & \multicolumn{5}{|c|}{ Days after inoculation } \\
\hline & 7 & 14 & 21 & 28 & 35 \\
\hline \multicolumn{6}{|l|}{ A. Mbuni } \\
\hline Alternaria & 1.6 & 2.4 & 4.0 & 4.5 & 4.6 \\
\hline Fungal mixture & 2.7 & 3.0 & 3.7 & 4.2 & 4.3 \\
\hline Trichoderma & 1.7 & 2.1 & 3.0 & 3.7 & 3.9 \\
\hline Epicoccum & 1.5 & 2.4 & 3.2 & 3.8 & 4.1 \\
\hline Cotaf $^{\circledR}$ (50 g/L hexaconacole) & 3.1 & 3.4 & 3.5 & 3.9 & 4.1 \\
\hline Pearl $^{\circledR}$ (500 g/L carbendazim) & 2.7 & 3.1 & 3.7 & 4.2 & 4.4 \\
\hline Thiovit $^{\circledR}$ (micronised sulphur $80 \%$ w/w) & 2.3 & 2.4 & 3.5 & 3.8 & 4.1 \\
\hline Water & 2.6 & 3.0 & 3.7 & 4.3 & 4.5 \\
\hline $\operatorname{LSD}_{(\mathrm{p}<0.05)}$ & 0.7 & NS & NS & NS & NS \\
\hline \multicolumn{6}{|l|}{ B. Njoro BW II } \\
\hline Alternaria & 2.0 & 2.4 & 2.7 & 3.5 & 3.8 \\
\hline Fungal mixture & 2.8 & 3.2 & 3.6 & 3.9 & 4.2 \\
\hline Trichoderma & 1.9 & 2.3 & 2.6 & 3.2 & 3.5 \\
\hline Epicoccum & 1.4 & 1.8 & 2.3 & 2.4 & 2.8 \\
\hline $\operatorname{Cotaf}^{\circledR}$ (50 g/L hexaconacole) & 2.4 & 2.8 & 3.1 & 3.5 & 3.8 \\
\hline Pearl $^{\circledR}$ (500 g/L carbendazim) & 2.8 & 3.2 & 2.4 & 3.9 & 4.3 \\
\hline Thiovit $^{\circledR}$ (micronised sulphur $80 \% \mathrm{w} / \mathrm{w}$ ) & 1.7 & 2.3 & 3.0 & 3.4 & 3.5 \\
\hline Water & 1.1 & 1.2 & 1.6 & 1.8 & 2.0 \\
\hline $\operatorname{LSD}_{(\mathrm{p}<0.05)}$ & 0.6 & 0.7 & 0.8 & 1.0 & 1.0 \\
\hline
\end{tabular}

LSD: least significant difference; NS: Not significant. mixture of fungal antagonists resulted in the highest AUDPC of 553. None of the antagonistic fungi and fungicides significantly increased the 10-ear and total grain weight for both cultivars Mbuni and Njoro BW II. Alternaria and Epicoccum were the least and most effective antagonists in reducing $F$. graminearum kernel infection in CV. Mbuni, respectively. This compared favourably with fungicide Thiovit ${ }^{\circledR}$ which resulted in $8 \%$ reduction in kernel infection with $F$. graminearum. There were significant $(\mathrm{p}<0.05)$ differences in reduction of kernel infection with $F$. graminearum among the fungicides and antagonists. However, neither the antagonists nor the fungicides resulted in significant $(\mathrm{p}<0.05)$ reduction of F. poae infection on both cultivars Mbuni and Njoro BW II.

\subsection{Susceptibility of Wheat Lines to FHB and T-2 Toxin Contamination}

All the wheat cultivars and lines tested were susceptible to $F$. poae and F. graminearum although there was variability in susceptibility levels (Table 4). Cultivars KIBIS and Njoro BW I were the most and least susceptible, respectively. There were significant $(p<0.05)$ differences in AUDPC among the lines and cultivars inoculated with F. poae. Standardized area under disease progress curve (AUDPC) was highest in line R1104 and lowest in Njoro BW II. Inoculation with a mixture of $F$. graminearum and $F$. poae to line R1098 reduced 10-ear grain weight by up to $50 \%$ compared to $26 \%$ on line R1104. Fusarium poae and $F$. graminearum were re-isolated in all the lines and cultivars. The highest re-isolation frequency of up to 90\% for F. poae was observed on cv. Njoro BW II while the lowest re-isolation of 50\%, was on line R1105. However, cv. Mbuni had the highest kernel infection with $F$. graminearum. All the cultivars and lines tested were contaminated with T-2 toxin at concentration levels varying from 4.9 to 27.8 ppb. Kernels from line R1098 had the highest T-2 toxin levels while line R1114 had the lowest contamination.

\section{Discussion}

All fungicides and microbial agents suppressed FHB but did not completely control the disease. In vitro activity of fungicides completely inhibited the growth of F. graminearum and F. poae. Riungu et al. [30] found that Copper oxychloride ${ }^{\circledR}$ and Folicur ${ }^{\circledR}$ completely suppressed the growth of F. graminearum in vitro. However, under field conditions, fungicides have low efficacy levels and hence the efforts to seek alternative FHB management strategies. Under greenhouse conditions, none of the fungicides completely controlled the FHB pathogens but only suppressed them concurring with earlier findings [31-33]. Use of fungicides in the management of FHB has been 
Table 3. Disease severity rating, grain weight (g), AUDPC and percentage re-isolation of $F$. poae and $F$. graminearum on cv. Mbuni and cv. Njoro BW II.

\begin{tabular}{|c|c|c|c|c|c|c|}
\hline \multirow{2}{*}{ Organism/Fungicide } & \multirow{2}{*}{ Disease severity (\%) } & \multirow{2}{*}{ AUDPC } & \multirow{2}{*}{10 ear weight } & \multirow{2}{*}{ Grain weight/pot } & \multicolumn{2}{|c|}{ Re-isolation frequency (\%) } \\
\hline & & & & & F. graminearum & F. poae \\
\hline \multicolumn{7}{|c|}{ A. Mbuni } \\
\hline Alternaria & 3.0 & 511.5 & 4.4 & 12.9 & 50.3 & 25.2 \\
\hline Fungal mixture & 3.1 & 552.8 & 3.4 & 9.2 & 20.7 & 44.7 \\
\hline Trichoderma & 2.6 & 416.3 & 3.4 & 8.2 & 16.7 & 47.8 \\
\hline Epicoccum & 2.7 & 437.7 & 4.1 & 10.1 & 9.3 & 52.1 \\
\hline $\operatorname{Cotaf}^{\circledR}$ & 3.2 & 561.2 & 2.8 & 10.5 & 26.9 & 49.0 \\
\hline Pearl $^{\circledR}$ & 3.2 & 561.9 & 2.3 & 6.0 & 8.3 & 38.6 \\
\hline Thiovit $^{\circledR}$ & 2.8 & 480.4 & 4.4 & 10.2 & 32.0 & 42.9 \\
\hline Water & 3.2 & 553.5 & 3.5 & 8.2 & 11.7 & 38.0 \\
\hline Untreated & 1.0 & 105.0 & 4.7 & 11.6 & 0.1 & 2.9 \\
\hline $\operatorname{LSD}_{(\mathrm{p}<0.05)}$ & 0.4 & 89.0 & NS & NS & 1.0 & NS \\
\hline \multicolumn{7}{|c|}{ B. Njoro BW II } \\
\hline Alternaria & 2.6 & 418.8 & 4.3 & 12.7 & 33.3 & 27.2 \\
\hline Fungal mixture & 3.1 & 543.2 & 3.2 & 9.5 & 11.0 & 26.7 \\
\hline Trichoderma & 2.4 & 384.8 & 2.7 & 7.4 & 34.7 & 20.0 \\
\hline Epicoccum & 2.0 & 295.2 & 3.0 & 6.8 & 14.0 & 40.0 \\
\hline $\operatorname{Cotaf}^{\circledR}$ & 2.8 & 470.4 & 2.8 & 9.5 & 16.5 & 43.1 \\
\hline Pearl $^{\circledR}$ & 3.1 & 545.1 & 3.3 & 11.3 & 1.5 & 66.7 \\
\hline Thiovit $^{\circledR}$ & 2.5 & 406.5 & 3.3 & 10.1 & 9.8 & 37.3 \\
\hline Water & 1.4 & 185.7 & 3.3 & 8.8 & 8.7 & 45.3 \\
\hline Untreated & 1.0 & 105.0 & 7.1 & 17.3 & 8.3 & 41.3 \\
\hline $\operatorname{LSD}_{(\mathrm{p}<0.05)}$ & 0.3 & 81.8 & 2.4 & 5.1 & 1.1 & NS \\
\hline
\end{tabular}

LSD: least significant difference; AUDPC: area under disease progress curve.

shown to be at most $77 \%$ and $89 \%$ effective in reduction of disease severity and mycotoxins content, respectively [32]. Additionally, efficacy of fungicides in managing FHB is highly variable and often unsatisfactory. This variability is related to the complex interactions between water, temperature, fungicide concentration and the time of inoculation [34].

Microbial agents in the current study did not completely reduce FHB contrary to the report by Kolombet et al. [35]. Among the antagonists, Trichoderma had the highest colony reduction of test pathogens in vitro. However, using Trichoderma as the antagonist there was a greater reduction in the colony diameter of $F$. poae compared to F. graminearum. This could be attributed to repression of expression of the Trichoderma chitinase gene nag1-gox - which contributes to biocontrol activity-by DON, the major mycotoxin produced by $F$. graminearum [36]. This could also be a possible explanation for the lowest grain yield per pot treated with Trichoderma sp. However, this was in contrast with the findings by Riungu et al. [30] who reported that Trichoderma reduced
FHB severity and increased grain yield. Diamond and Cooke [37] reported a 60\% reduction in FHB symptoms relative to control treatment after 25 days on ears preinoculated with the biocontrol agent Phoma betae and challenged with F. culmorum.

After treatment of wheat with the antagonists, the reisolation frequency of $F$. graminearum was lower than for $F$. poae. Considering that the plants had been inoculated with composite inoculums of the two pathogens with equal number of conidia, differences in re-isolation frequency could be due to variability in competitive ability of the fungal isolates and species $[38,39]$. However, among the biological agents, treatment with Alternaria resulted in the highest $F$. graminearum re-isolation frequency while treatment with Epicoccum resulted in the lowest. This implies greater antagonism of F. graminearum from Epicoccum compared to the other biological agents. High antagonism of Epicoccum against F. graminearum has been reported by other researchers $[40,41]$.

All tested wheat lines and cultivars were found to be susceptible to FHB concurring with the findings of other 
Table 4. Disease severity, standard AUDPC, grain weight, re-isolation frequency (\%) of $F$. poae and $F$. graminearum and T-2 concentration (ppb).

\begin{tabular}{|c|c|c|c|c|c|c|c|}
\hline \multirow{2}{*}{ Cultivar/line } & \multirow{2}{*}{ Disease Severity ${ }^{1}$} & \multirow{2}{*}{ Std AUDPC } & \multirow{2}{*}{10 ear grain wgt } & \multirow{2}{*}{ Grain wgt (g)/pot } & \multirow{2}{*}{ T-2 Toxin } & \multicolumn{2}{|c|}{ Re-isolation (\%) } \\
\hline & & & & & & F. poae & F. gra \\
\hline KIBIS & 6.0 & 17.5 & 7.6 & 23.3 & 15.2 & 70.7 & 4.0 \\
\hline Mbuni & 4.4 & 13.1 & 8.7 & 26.3 & 18.8 & 63.8 & 20.0 \\
\hline Njoro BW I & 1.7 & 4.7 & 5.7 & 20.8 & 18.1 & 81.7 & 0.0 \\
\hline Njoro BW II & 3.6 & 10.1 & 6.5 & 25.6 & 19.7 & 90.6 & 1.6 \\
\hline R1098 & 5.3 & 15.1 & 12.2 & 38.9 & 18.3 & 72.9 & 7.6 \\
\hline R1107 & 4.9 & 13.7 & 11.5 & 34.9 & 19.7 & 67.3 & 6.7 \\
\hline R1111 & 4.5 & 12.1 & 12.1 & 36.6 & 17.0 & 60.0 & 4.8 \\
\hline R1112 & 2.2 & 6.1 & 5.6 & 21.1 & 24.0 & 69.7 & 1.5 \\
\hline R1114 & 6.2 & 17.9 & 10.0 & 29.1 & 4.9 & 56.7 & 10.7 \\
\hline R1115 & 2.3 & 6.1 & 4.9 & 21.2 & 23.6 & 60.4 & 4.5 \\
\hline R1119 & 4.8 & 13.7 & 12.4 & 35.5 & 21.3 & 64.2 & 10.8 \\
\hline R1121 & 3.5 & 9.6 & 6.0 & 26.3 & 27.8 & 68.3 & 2.1 \\
\hline R1100 & 4.9 & 15.1 & 13.0 & 39.7 & 16.6 & 62.8 & 11.7 \\
\hline R1128 & 5.4 & 19.6 & 11.8 & 38.5 & 16.9 & 55.2 & 0.7 \\
\hline R1130 & 5.8 & 20.7 & 10.3 & 34.2 & 17.6 & 66.0 & 2.0 \\
\hline R1101 & 4.7 & 13.3 & 12.2 & 32.5 & 12.5 & 51.7 & 19.2 \\
\hline R1104 & 6.4 & 23.4 & 11.3 & 38.8 & 22.8 & 51.7 & 6.0 \\
\hline R1105 & 5.9 & 17.0 & 15.6 & 33.0 & 17.6 & 50.3 & 10.7 \\
\hline R1106 & 5.6 & 15.2 & 11.2 & 42.1 & 16.3 & 71.0 & 6.9 \\
\hline $\operatorname{LSD}_{(\mathrm{p}<0.05)}$ & 0.6 & 1.5 & 3.9 & 9.2 & & 1.5 & 0.6 \\
\hline Cv (\%) & 1.2 & 0.9 & 0.9 & 0.4 & & 2.2 & 5.2 \\
\hline
\end{tabular}

${ }^{1}$ Values are means of FHB severity taken weekly until 35 days post-inoculation; LSD: least significant difference; Cv: Coefficient of variation; F. gra: F. graminearum.

researchers [42-44] who found all cultivars grown in Kenya were susceptible to FHB. However, cv. Njoro BW I was found to be the least susceptible to FHB, a finding consistent with that of Muthomi et al. [44] who described the cultivar as tolerant. Further breeding to improve resistance of the cultivar to FHB could be desirable. Despite the low susceptibility level of cv. Njoro BW I, it had the lowest grain weight per pot. Lack of consistency in the two parameters could be attributed to the fact that some wheat cultivars or lines are susceptible to FHB but can tolerate the disease with minimal effect on yield. Differences in host susceptibility to FHB could be due to inherent genetic resistance factors $[15,38]$.

Host resistance has long been considered the most practical and effective means of FHB management. However, breeding has been hindered by lack of effective resistance genes and by the complexity of the resistance in identified sources [45]. Additionally, development of resistant cultivars has been slowed down by poorly adapted and incomplete resistance sources and confounding environmental effect that make screening of germplasm difficult [46]. No source of complete resistance is known in the world, and current sources provide only partial resistance or tolerance to FHB $[17,18,45]$. The challenge is further compounded by the fact that the best regionally adapted and highly productive cultivars are susceptible to the disease $[47,48]$. Despite lack of totally resistant wheat genotype in the world today, there is hope in breeding initiatives particularly exploiting the Chinese spring variety Sumai3 and its derivatives, which carry the most effective resistance quantitative trait loci (QTL) Fhb1 and Qfhs.ifa-5A [46-48].

All tested wheat lines and cultivars were found to be susceptible to T-2 toxin contamination with the concentration varying from 5 to $28 \mathrm{ppb}$. High T2-toxin contamination levels of different lines and cultivars shows lack of resistance to Fusarium in Kenya wheat germplasm. T-2 toxin is one the major mycotoxins produced by $F$. poae and is known to pose serious threats to human and animal health [49]. T-2 toxin inhibits protein synthesis, which is followed by a secondary disruption of DNA, and RNA synthesis. It affects the actively dividing cells 
such as those lining the gastrointestinal tract, skin, lymphoid, and erythroid cells. The toxin can decrease antibody levels, immunoglobulins and certain other humoral factors. The effects include weight loss or poor weight gain, bloody diarrhea, dermal necrosis or beak lesions, hemorrhage and decreased production [50]. Contamination of wheat grains from commercial wheat cultivars and lines under test with T-2 toxin poses a threat to food and feed industry. Past research has shown that the most promising and effective strategy of managing FHB and the associated toxins is by the use of varieties that resist mould growth and mycotoxin production [51-53]. Therefore, further breeding efforts are required to improve lines and cultivars with promising resistance to FHB and T2-toxin contamination. Where fungicides and/or biocontrol products are applied, proper timing and application are critical. Integrated approach of managing FHB of wheat is recommended.

\section{Acknowledgements}

This research was funded by the International Foundation for Science (IFS Grant C3654-2).

\section{REFERENCES}

[1] D. Tan, E. Ghisalberti, G. Flematti, M. J. Barbetti and K. Sivasithamparam, "Mycotoxic Metabolites Produced by Fusarium Species Associated with Fusarium Head Blight and Feed Refusal Disorders in Western Australia,” Journal of Plant Pathology, Vol. 90, 2008, pp. 53-60.

[2] C. E. Windels, "Economic and Social Impacts of Fusarium Head Blight: Changing Farms and Rural Communities in the Northern Great Plains," Journal of Phytopathology, Vol. 90, No. 1, 2000, pp. 17-21. doi:10.1094/PHYTO.2000.90.1.17

[3] M. Weidenbörner, "Mycotoxins in Foodstuffs," SpringerVerlag, Berlin, 2008.

[4] C. J. R. Cumagun and T. Miedaner, "Segregation for Aggressiveness and Deoxynivalenol Production of a Population of Gibberella zeae Causing Head Blight of Wheat," European Journal of Plant Pathology, Vol. 110, No. 8, 2004, pp. 789-799. doi:10.1007/s10658-004-0895-Z

[5] B. N. Reddy and C. R. Raghavender, "Reports of Fusarial-Toxin Poisoning in India," Journal of Plant Pathology, Vol. 90, 2008, pp. 53-60.

[6] C. Jansen, D. von Wettstein, W. Schäfer, K. H. Kogel, A. Felk and F. J. Maier, "Infection Patterns in Barley and Wheat Spikes Inoculated with Wild-Type and Trichodiene Synthase Gene Disrupted Fusarium graminearum," Proceedings of the National Academy of Sciences, Vol. 102, No. 46, 2005, pp. 16892-16897.

[7] F. J. Maier, T. Miedaner, B. Hadeler, A. Felk, S. Salomon, M. Lemmens, H. Kassner and W. Schäfer, "Involvement of Trichothecenes in Fusarioses of Wheat, Barley and Maize Evaluated by Gene Disruption of the Trichothecene Synthase (Tri5) Gene in Three Field Isolates of Dif- ferent Chemotype and Virulence,” Molocular Plant Pathology, Vol. 7, No. 6, 2006, pp. 449-461. doi:10.1111/j.1364-3703.2006.00351.x

[8] D. W. Brown, R. A. E. Butchko, M. Busman and R. H. Proctor, "The Fusarium verticillioides FUM Gene Cluster Encodes a $\mathrm{Zn}(\mathrm{II})_{2} \mathrm{Cys}_{6}$ Protein that Affects FUM Gene Expression and Fumonisin Production,” Eukaryotic Cell, Vol. 6, No. 7, 2007, pp. 1210-1218. doi:10.1128/EC.00400-06

[9] W. Kriel, "Fusarium Head Blight of Wheat: A Most Challenging Disease,” South African Society of Plant Pathology, 2006. http://saspp.org

[10] T. Heier, S. K. Jain, K. H. Kogel and J. Pons-Kühnemann, "Influence of N-Fertilization and Fungicide Strategies on Fusarium Head Blight Severity and Mycotoxins Content in Winter Wheat,” Journal of Phytopathology, Vol. 153, No. 9, 2005, pp. 551-557. doi:10.1111/j.1439-0434.2005.01021.x

[11] H. R. Forrer, A. Hecker, E. Jenny, T. Bucheli, F. Wettsein and S. Vogelsang, "Control of Fusarium graminearum with Anti Fungal Plant Preparations and Their Effect on Mycotoxin Contamination of Wheat," Journal of Plant Pathology, Vol. 90, 2008, pp. 41-43.

[12] D. W. Parry, P. Jenkinson and L. McLeod, "Fusarium Ear Blight (Scab) in Small Grains-A Review,” Plant Pathology, Vol. 44, No. 2, 1995, pp. 207-238. doi:10.1111/j.1365-3059.1995.tb02773.x

[13] R. K. Jones, "Assessments of Fusarium Head Blight of Wheat and Barley in Response to Fungicide Treatment," Plant Disease, Vol. 84, No. 9, 2000, pp. 1021-1030. doi:10.1094/PDIS.2000.84.9.1021

[14] J. A. Lewis, G. C. Papavizas and M. D. Hollenbeck, "Biological Control of Damping-Off of Snapbeans Caused by Sclerotium rolfsii in the Greenhouse and Field with Formulations of Gliocladium virens," Biological Control, Vol. 3, No. 2, 1993, pp. 109-115. doi:10.1006/bcon.1993.1017

[15] C. Von der Ohe and T. Miedaner, "Competitive Aggressiveness in Binary Mixtures of Fusarium graminearum and F. culmorum Isolates Inoculated on Spring Wheat with Highly Effective Resistance QTL,” Journal of Phytopathology, Vol. 159, No. 6, 2011, pp. 401-410.

[16] G.-H. Bai, G. Shaner and H. Ohm, "Inheritance of Resistance to Fusarium graminearum in Wheat," Theoretical and Applied Genetics, Vol. 100, No. 1, 2000, pp. 1-8. doi:10.1007/PL00002902

[17] H. Wisniewska and K. Kowalczyk, "Resitance of Cultivars and Breeding Lines of Spring Wheat to Fusarium culmorum and Powdery Mildew," Journal of Applied Genetics, Vol. 46, No. 1, 2005, pp. 35-40.

[18] S. A. Pereyra and R. Dill-Macky, "Survival and Inoculum Production of Gibberella zeae in Wheat Residue," Plant Disease, Vol. 88, No. 7, 2004, pp. 724-730. doi:10.1094/PDIS.2004.88.7.724

[19] D. A. Schisler, N. I. Khan, M. J. Boehm and P. J. Slininger, "Green House and Field Evaluation of Microbial Agents of Fusarium Head Blight on Durum Wheat," Plant Disease, Vol. 86, 2002, pp. 1350-1356. 
[20] D. A. Schisler, N. I. Khan and M. J. Boehm, "Biological Control of Fusarium Head Blight of Wheat and Deoxynivalenol Levels in Grain via Use of Microbial Antagonists," Advances in Experimental Medicine and Biology, Vol. 504, Part 1, 2002, pp. 53-69.

doi:10.1007/978-1-4615-0629-4_6

[21] I. Bujold, T. C. Paulitz and O. Carisse, "Effect of Microsphaeropsis sp. on the Production of Perithecia and Ascospores of Gibberella zeae,” Plant Disease, Vol. 85, No. 9, 2001, pp. 977-984. doi:10.1094/PDIS.2001.85.9.977

[22] G. Y. Yuen and S. D. Schoneweis, "Strategies for Managing Fusarium Head Blight and Deoxynivalenol Accumulation in Wheat," International Journal of Food Microbiology, Vol. 119, No. 1-2, 2007, pp. 126-130. doi:10.1016/j.ijfoodmicro.2007.07.033

[23] N. I. Khan, D. A. Schisler, M. J. Boehm, P. J. Slininger and R. J. Bothast, "Selection and Evaluation of Microorganisms for Microbial of Fusarium Head Blight of Wheat Incited by Gibberella zeae,” Plant Disease, Vol. 85, No. 12, 2001, pp. 1253-1258. doi:10.1094/PDIS.2001.85.12.1253

[24] J. M. Wagacha and J. W. Muthomi, "Fusarium culmorum: Infection Process, Mechanisms of Mycotoxins Production and Their Role in Pathogenesis in Wheat," Crop Protection, Vol. 26, No. 7, 2007, pp. 877-885. doi:10.1016/j.cropro.2006.09.003

[25] G. Bai and G. Shaner, "Scab of Wheat: Prospects for Control,” Plant Disease, Vol. 78, No. 8, 1994. 760-766. doi:10.1094/PD-78-0760

[26] J. C. Zadoks, T. T. Chang and C. F. Konzak, “A Decimal Code for the Growth Stages of Cereals,” Weed Research, Vol. 14, No. 6, 1974, pp. 415-421. doi:10.1111/j.1365-3180.1974.tb01084.x

[27] G. Shaner and R. A. Finney, "The Effect of Nitrogen Fertilization on the Expression of Slow-Mildewing Resistance in Knox Wheat,” Phytopathology, Vol. 67, 1977, pp. 1051-1056. doi:10.1094/Phyto-67-1051

[28] Association of Official Analytical Chemists, "Official Methods of Analysis,” 16th Edition, AOAC International, Arlington, 1995.

[29] J. K. Gathumbi, E. Usleber and E. Maertlbauer, "Production of Ultra Sensitive Antibodies against Aflatoxin B1," Letters in Applied Microbiology, Vol. 32, No. 5, 2001, pp. 349-351. doi:10.1046/j.1472-765X.2001.00914.x

[30] G. M. Riungu, J. M. Muthomi, R. D. Narla and J. K. Gathumbi, "Fusarium Head Blight, DON and Fusarium Contamination of Wheat and Maize," Journal of Plant Pathology, Vol. 1, 2008, pp. 13-19.

[31] C. Müllenborn, U. Steiner, M. Ludwig and E.-C. OerKe, "Effect of Fungicides on the Complex of Fusarium and the Saprophytic Fungi Colonizing Wheat Kernels," European Journal of Plant Pathology, Vol. 120, No. 2, 2008, pp. 157-166.

[32] M. Haidukowski, M. Pascale, G. Perrone, D. Pancaldi, C. Campagna and A. Visconti, "Effect of Fungicides on the Development of Fusarium Head Blight, Yield and Deoxynivalenol Accumulation in Wheat Inoculated under
Field Conditions with Fusarium graminearum and Fusarium culmorum,” Journal of Science, Food, and Agriculture, Vol. 85, No. 2, pp. 191-198. doi:10.1002/jsfa.1965

[33] A. Mesterhazy, J. Bartok and C. Lamper, "Influence of Wheat Cultivars, Species of Fusarium and Isolate Aggressiveness on the Efficacy of Fungicides for Control of FHB,” Plant Disease, Vol. 87, No. 9, 2003, pp. 110-115. doi:10.1094/PDIS.2003.87.9.1107

[34] L. Ramirez, S. Chulze and N. Magan, "Impact of Environmental Factors on Growth and Deoxynivalenol Production by Fusarium graminearum Isolates from Argentinian Wheat,” Crop Protection, Vol. 23, No. 2, 2004, pp. 117-125. doi:10.1016/j.cropro.2003.07.005

[35] L. V. Kolombet, A. A. Starshov and D. A Schisler, "Greenhouse Testing Trichoderma asperellum GJS 03-35 and Yeast Cryptococcus nodaensis OH 182.9 as Microbial agents against Fusarium Head Blight of Wheat," Mycology and Phytopathology, Vol. 5, 2005, pp. 80-88.

[36] P. L. Matthias, G. Feichtinger, G. Défago and B. Duffy, "Mycotoxigenic Fusarium and Deoxynivalenol Production Repress Chitinase Gene Expression in the Biocontrol Agent Trichoderma atroviride P1," Applied and Environmental Microbiology, Vol. 69, No. 6, 2003, pp. 3077 3084. doi:10.1128/AEM.69.6.3077-3084.2003

[37] H. Diamond and B. M. Cooke, "Preliminary Studies on Biological Control of Fusarium Ear Blight Complex of Wheat," Crop Protection, Vol. 22, No. 1, 2003, pp. 99107. doi:10.1016/S0261-2194(02)00117-5

[38] H. H. Voss, R. L. Bowden, J. F. Leslie and T. Miedaner, "Segregation of Heightened Aggressiveness to Wheat in Two Fusarium graminearum Crosses," Phytopathology, Vol. 100, No. 9, 2010, pp. 904-912. doi:10.1094/PHYTO-100-9-0904

[39] T. Miedaner and H. H. Voss, "Effect of Dwarfing Rht Genes on Fusarium Head Blight Resistance in Two Sets of Near-Isogenic Genotypes of Wheat and Check Cultivars," Crop Science, Vol. 48, 2008, pp. 2115-2122. doi:10.2135/cropsci2008.02.0107

[40] J. W. Muthomi, G. M. Riungu, J. K. Ndungú, R. D. Narla, J. K. Gathumbi and J. M. Wagacha, "Head Blight of Wheat in Kenya and Contamination of Grain with Mycotoxin Producing Fusarium Species," Journal of Plant Sciences, Vol. 3, No. 1, 2008, pp. 52-60. doi:10.3923/jps.2008.52.60

[41] V. Sab, J. Milles, J. Kramer and A. Prange, "Competitive Interactions of Fusarium graminearum and Alternaria alternate in Vitro in Relation to Deoxynivalenol and Zearalenone Production,” International Journal of Food, Agriculture and Environment, Vol. 5, 2007, pp. 257-261.

[42] J. K. Ndung'u, "Fungal and Mycotoxin Contamination of Wheat from Nakuru and Nyandarua Districts of Kenya and Pathogenecity of Fusarium Species on Wheat,” M.Sc. Thesis, University of Nairobi, Nairobi, 2006.

[43] J. W. Muthomi, E.-C. Oerke, H.-W. Dehne and E. W. Mutitu, "Susceptibility of Kenyan Wheat Varieties to Head Blight, Fungal Invasion and Deoxynivalenol Accumulation Inoculated with Fusarium graminearum," Journal of Phytopatholology, Vol. 150, No. 1, 2002, pp. 30-36. doi:10.1046/j.1439-0434.2002.00713.x 
[44] J. W. Muthomi, J. K. Ndungú, G. N. Chemining’wa and J. M. Wagacha, "Reaction of Some Kenyan Wheat Cultivars to Head Blight after Inoculation with Fusarium graminearum,” Asian Journal of Plant Sciences, Vol. 6, No. 4, 2007, pp. 585-591. doi:10.3923/ajps.2007.585.591

[45] J. C. Rudd, R. D. Horsley, A. L. Mckendry and E. M. Elias, "Host Plant Resistance Genes for Fusarium Head Blight: Sources, Mechanisms, and Utility in Conventional Breeding Systems,” Journal of Crop Science, Vol. 41, No. 3, 2001, pp. 620-627. doi:10.2135/cropsci2001.413620x

[46] J. A. Anderson, "Marker-Assisted Selection for Fusarium Head Blight Resistance in Wheat," International Journal of Food Microbiology, Vol. 119, No. 1-2, 2007, pp. 51-53. doi:10.1016/j.jjfoodmicro.2007.07.025

[47] H. Buerstmayr, T. Ban and J. A. Anderson, "QTL Mapping and Marker-Assisted Selection for Fusarium Head Blight of Wheat: A Review,” Plant Breeding, Vol. 128, No. 1, 2009, pp. 1-26. doi:10.1111/j.1439-0523.2008.01550.x

[48] H. Buerstmayr, B. Steiner, L. Hartl, M. Griesser, N. Angerer, D. Lengauer, T. Miedaner, B. Schneider and M. Lemmens, "Molecular Mapping of QTLs for Fusarium Head Blight Resistance in Spring Wheat. II. Resistance to Fungal Penetration and Spread," Theoretical and Applied
Genetics, Vol. 107, No. 3, 2003, pp. 503-508. doi:10.1007/s00122-003-1272-6

[49] J. W. Bennett and M. Klich, "Mycotoxins," Clinical Microbiology Reviews, Vol. 16, No. 3, 2003, pp. 497-516. doi:10.1128/CMR.16.3.497-516.2003

[50] World Health Organization, "Food Additives Series 47, FAO Food and Nutrition Paper 74," 56th Meeting of the Joint FAO/WHO Expert Committee on Food Additives (JECFA), WHO, Geneva, 2001, p. 557.

[51] L. S. L. Wong, D. Abramson, A. Tekauz, D. Irisle and R. I. H. McKenzie, "Pathogenicity and Mycotoxin Production of Fusarium Species Causing Head Blight in Wheat Cultivars Varylng in Resistance," Canadian Journal of Plant Science, Vol. 75, No. 1, 1995, pp. 261-267. doi:10.4141/cjps95-047

[52] A. Mesterhazy, "Types and Components of Resistance to Fusarium Head Blight of Wheat,” Plant Breeding, Vol. 114, No. 5, 1995, pp. 377-388. doi:10.1111/j.1439-0523.1995.tb00816.x

[53] J. D. Miller, J. C. Young and D. R. Sampson, “Deoxynivalenol and Fusarium Head Blight Resistance in Spring Cereals," Phytopathology, Vol. 113, No. 4, 1985, pp. 359-367. 